\title{
Personal Ethics in a Corporate World
}

\author{
Ronald D. Francis and Anona Armstrong \\ Victoria University, Australia
}

\begin{abstract}
This paper addresses the relationship between personal morality and ethical corporate behaviour. The main issue addressed here is the positing of the concept of moral intelligence - the relationship of personal moral stance and corporate behaviour. Just as there is intellectual competence (IQ) and emotional intelligence (EIQ), so too there is moral intelligence. This paper outlines the theoretical and practical basis for the case. Mention is made of confounding issues, such as the stability of moral intelligence, the way in which situational context may over-ride it, and how it might be identified in a manner that is economical, reliable, and valid. It is argued that the development of the concept, and a test, has substantial commercial benefits.
\end{abstract}

\section{Keywords}

Personal morality, ethical corporate behaviour, emotional intelligence, moral intelligence

\section{Introduction}

This conceptual paper is designed to assess the value of moral intelligence to business. In so doing it considers the issue of the selection of board members, managers, and employees. It is argued that the selection, and the training, for moral intelligence has consequences for both the long-term profitability, and the overall reputation for commercial dealings. Additionally, such a trend should result in an improvement of the overall quality of life. Thus, the aim of the study is to determine the components of moral intelligence. It addresses the relationship between personal morality and ethical corporate behaviour. The main issue here is to map the concept of moral intelligence.

Morality is about the beliefs and values that guide people in their decisions. Ethics is about the decisionmaking, and based upon an expressed code of values and of conduct. The main question here is the identification of any personal qualities that contribute to the relationship of personal moral stance and corporate behaviour. Just as there is intellectual competence (IQ) and emotional intelligence (EIQ), so too there might be a moral intelligence (or moral intelligence quotient - MIQ).

Here there is an important distinction to be made. Emotional intelligence is to do with sensitivity to the wishes and feelings of others: moral intelligence is similar but with the vital distinction of moral intelligence having human values as a reference point. One might say that a salesperson should have emotional intelligence: indeed, without it the insensitivity would diminish the chances of a sale, and a career. Moral intelligence detects wishes and feelings, but makes judgements in terms of conforming to

Copyright (C) 2008 Victoria University. This document has been published as part of the Journal of Business Systems, Governance and Ethics in both online and print formats. Educational and non-profit institutions are granted a nonexclusive licence to utilise this document in whole or in part for personal or classroom use without fee, provided that correct attribution and citation are made and this copyright statement is reproduced. Any other usage is prohibited without the express permission of the agreed values rather than on mere understanding, or of satisfying a need.

Here the issue is to map the concept of moral intelligence, and the suggestion that a test of an internalised quality of moral commitment and behaviour is worthy of development. Any investigations must accommodate the relationship between personality, ethical experience and demographic information. Having 
established the validity of the concept of moral intelligence the ensuing task is clearly that of developing a valid and reliable measure.

\section{The Overall Importance of the Proposal}

There is increasing agreement that ethics in business is influenced by many factors: individual, economic, social and cultural operating both within and outside an organization (Logsdon and Corzine, 1999). The focus of the proposed study is limited to the question of what are the individual personal characteristics of those who are ethical and those who are not and how might they be readily and economically identified. A further requirement of this overall concept is that any test developed should be linked to identifiable behavioural markers and not be restricted to attitudinal items.

\section{Background}

It is to be noted that a search of the literature using ABI/Inform, Ebsohost, PsycINFO, and SocioFile failed to yield reference to any such test. A reading of the Mental Measurements Yearbook (2005), similarly, yielded no such test. A perusal of the catalogs of the major suppliers of psychological tests (eg. ACER, Savile Holdsworth, The Psychological Corporation, etc.) did not yield any tests. There are some tests that have sub-scales of honesty, and the like but no direct and complete test. Further, such subscales as are available are attitudinal ones, and that may not necessarily relates to what respondents have actually done, or might do.

One could readily imagine someone being honest with family and friends, and much less so in business. This is recognised as a complex issue. In noting that the point needs to be made that moral intelligence is most probably as normally distributed as are other characteristics, such as cognitive intelligence, emotional intelligence, and extraversion. Any test developed here would be an indicator of that level, much as one measures other personal qualities. The notion that moral responses are situationally determined has been canvassed widely by Zimbardo (2007). His classic Stanford Prison Experiment showed that ordinary decent people would, in the right (wrong) circumstances, behave brutally. His work with the guards from Abu Ghraib prison affirmed that notion. Here the basic question concerns human moral malleability, and how sensitive it is to situation. That point is addressed further below.

As the moral stance of a leader is a critical variable it is surprising to see so few studies which examine that aspect. One of the few published studies was conducted by Logsdon \& Corzine (1999). Their proposition number five held that a CEO's stage of moral development (in the Kohlbergian sense) is related to the organisation's ethical culture: CEOs whose ethical reasoning is more utilitarian are more likely to form and maintain negative ethical climates.

There are other ways of approaching this problem. One is that of looking at meta-studies, which are rarer: one might also look at selectors using clinical versus actuarial judgements. Litwack (2001) argued that, at this stage, there is no case to be made for replacing clinical judgements with actuarial ones. And yet another approach is looking at actuarial risk.

Of the various studies that could help illuminate the concept are ones that utilise data on prisoners incarcerated for offences that are clearly breaches of trust, as well as breaches of law. A second example is that of using a standard personality test that contains many items to see if a personality profile emerges that characterises the employees of high reputation organisations compared to organisations that have a reputation for marginal ethical behaviour. A third test could be that of conducting such a standard test on those who have been whistleblowers, and whose actions were clearly motivated by moral concern. 


\section{Research considerations}

Much of the research into ethics in business and society has focused on theoretical developments that attempt to explain the relationships between ethics and organizational attributes. For example, Armstrong, Sweeney et al, 1999), examined the relationships between ethical theories and the four dimensions of organizational climate that Victor and Cullen (2001) used to describe organizations. The study related behaviours that corresponded to the three theories with Kohlberg's (1969: 1976) theory of moral development.

Other studies, such as that of the substantial study by Trevino et al (1998) are essentially normative studies. That approach is an attempt to tease out the influence of such variables as organisational commitment, and deal with such concepts as organisational climate. It differs from the present analysis in that the Trevino et al study is normative, and reports empirical data: this present paper is individually based, and is conceptual rather than empirical.

In the early history of the mental testing movement there was a perceived need to make a quick and reliable assessment of cognitive ability. It was from that beginning that the concept of IQ was developed. The notion of testing for cognitive ability has thus been around for well over a century, and remained one of the best regarded and highly used personal capacity measurements. Apart from personality testing emotional capacity received a very low level of attention until the publication on the concept of emotional intelligence by Goleman in (2001). The concept is now referred to as the 'Emotional intelligence quotient' (EIQ). The idea that intelligence might have a number of components and a number of sub-categories received early attention from those as notable as Sir Francis Galton, to more recent commentators such as Sternberg (1995).

One of the consequences of this present idea is that of drawing of attention to forms of intelligence other than the strictly cognitive. It is noted that cognitive testing, now supplemented by testing for emotional intelligence, might have yet a third kind added, a moral intelligence representing personal qualities that contribute to the relationship of personal moral stance with their corporate behaviour. The issues that must be addressed are what are the components of this construct and how should it be measured?

Studies have shown that ethical decision making is related to perceived risk and locus of control (Cherry 1997); interpersonal competitiveness, locus of control, religious beliefs, age, gender, and competitiveness all relate to stated ethical decisions on insider-trading (Terpstra et al, 1993). Self monitoring is closely related to values, cognitive variables; and problems in using the Employment Inventory (in relation to workplace fraud) (Mikulay \& Goffin, 1998).

There is doubtful value of using the Employment Inventory alone, and probably better value in measuring 'conscientiousness' (Murphy \& Lee 1994). Social conscientiousness (Collins \& Schmidt 1993); and socialised control (Woolley \& Hakstian 1992) are relevant, as is the connection between honesty and other personality variables, as measured by the California Personality Inventory (CPI) and the Multidimensional Personality Questionnaire ( Lilienfeld, Andrews, Stone \& Stone (1994); emotional stability (Logan, Koettel \& Moore 1986). There was reference to a test in Baehr et al (1993). That reference mentioned a business ethics scale consisting of 20 items. It is a proprietary test and is attitudinal rather than behavioural.

The Kohlberg notion of the stages of moral development noted that the early moral view of the world by a child is something akin to psychopathy: they seem unable to conceive that others might have legitimate although divergent views of core relationships, and that sensitivity to the feelings of others is a prerequisite to social life, and that being a short-run social hedonist is not the moral way. Although we have nominated extremes here it is worth noting that, like most human qualities, it is distributed normally, following the Gaussian curve.

Clinical evidence does suggest that the capacity to be internally ethically dictated is a quality that is normally distributed - that individuals have it in varying degrees. That is to say, there are some whose moral stature is strong enough to withstand improper external pressures; and there are those whose 
actions are externally dictated. This Gaussian distribution is the quality that this proposal suggests as worthy of investigation.

In this respect a number of variables have been identified from the literature in a series of minor studies: among such concepts are attitudes to time; a sense of distrust about basic human natures; generosity of spirit; familial sense; sensitivity to stress; attitude to risk; social desirability, and collectivist versus individualistic outlook. A person's level of ethical behaviour relates to interpersonal competitiveness. Locus of control, religious beliefs, age, and gender are all related (Terpstra et al, 1993).

\section{Approaches}

There are various ways of approaching the issue of identifying moral sense. Such approaches may be characterised as falling along a continuum. At one end is that of social biology - that our genes carry the imprint of evolution, and express and foster those strategies that have had survival value. Following along those lines is the neurological approach. There is a concept labelled psychopathy (also called sociopathy) (as set out in the American Psychiatric Association manual (DSM IV)). Here the defining characteristics are those of being guiltless, loveless, and amoral. The hypothesised underlying cause is that of neurological immaturity. Just as small children behave immaturely so we expect them to grow out of it. Adult psychopaths may be grown in other respects but have failed to develop the later stages of sensitivity, as given in the Kohlberg analysis.

This manifestation of amoral behaviour finds formal expression in criminal courts, and in the appellation 'White collar crime'. For example, Blickle et al (2006) conducted a study on 150 German managers and 76 white collar criminals who formerly held such positions. The scales used were hedonism, conscientiousness, narcissism, social desirability, and behavioural control. They found that a logistic regression analysis accounted for $69 \%$ of the inter-group variance. Business white collar crime is predicted by gender (males being more likely to commit), low behavioural self-control, high hedonism, high narcissism, and high conscientiousness - after controlling for social desirability. The conclusion that high conscientiousness predicts white-collar crime seems to be at odds with the expected conceptual frame of reference, a point discussed by the authors. It was concluded that high ranking white-collar crime in business combines low integrity with high conscientiousness.

Another approach is that of using biodata. Such information would include; age, sibling position, marital history, qualifications, work history, illnesses, and hobbies/interests. Here the correlations might give an indication of the variables that operate to determine moral intelligence. This method is one that has been used with some success in determining suitability for certain occupations, but should be used with caution.

\section{Methodological issues}

To capture, and reiterate, the notion being put forward here involves four data sets: one on physiological measures (such as reaction time to certain stimuli - delayed and low reactions are characteristic of psychopathy); the second is the use of biodata (such as age, sibling position, work history, etc); the third is that of existing pencil and paper tests of the conventional psychological kind; and the fourth designed to measure the attributes identified by the professional practitioners which may not be captured in the existing tests (eg. judgements from 'thin slices of behaviour'. It will be appreciated that any target test will be one that is both reliable and valid. Further, it must not be too complex, nor too evident in its purpose lest responders' perceptions influence their conduct in the test.

The use of a conceptually simple but complex method of analysis method provides a protection against informed guesswork that might beat such a test. In addition to theses studies one of the aims of the project is to attempt to develop behavioural tests that could be effectively used to identify moral commitment. 
Some other methodological issues mar many studies. Those difficulties include tests conducted on undergraduates and then reporting the results as though they had external validity in the business world; a second problem is that of using constellations of subscales on standard tests and reporting on small samples as though the researcher were using the whole validated scale. A third problem is that of not taking domain specificity into account. This besetting problem bedevils many studies.

One of the more enterprising approaches that would be used here is to look at the converse of ethical behaviour, and examine such concepts as psychopathology. The idea of using the converse approach is that of measure involving either reversing a test, or applying a particular test and reversing the norms. What is needed is a validation of that approach.

The majority of the populace are neither psychopaths nor saints, and thus it is important in this field of endeavour that we identify the disposition toward ethical behaviour. There is increasing agreement that ethics in business is influenced by many factors: individual, economic, social and cultural operating both within and outside an organization.

The focus of the proposed study may be limited to the question of what are the individual personal characteristics of those who are ethical and those who are not, and how such persons might they be readily and economically identified. A further requirement is that any test developed should be linked to identifiable behavioural markers and not be restricted to attitudinal items. A search of literature and databases did not yield any detailed analysis or effective tests that would meet this need. The purpose of the proposed study is to fill that gap.

The notion of having to have extensive testing is not essential. Ambady \& Rosenthal (1993) have shown that 'thin' slices of behaviour may be quite effective, a point confirmed by Frank \& Ekman (1997) (see also Lubinski, 2000: Wehrle et al, 2000). The idea that testing should be time consuming and intrusive is a deterrent to the construction of a moral commitment test. Thus it is proposed any test developed be economical of time and resources.

\section{Issues in the development of a discrimination test}

It seems most improbable that moral intelligence will be comprised of a single quality. For example, a morally intelligent person would not only have firm standards, but would also believe them to be important; further, such a person would also have a strong internal locus of control, and thus be able to resist contextual pressures that would lead them to betray their principles.

Examples of previous studies on this point are to be found in one theoretical model which considered several hypothesised relations relative to the major independent variables of risk and locus of control; and the dependent variables of choice of moral rationale, ethical judgments, and behavioural intentions. As mentioned earlier, Cherry (1997) concluded that locus of control is the best available measure of moral autonomy; and increased risk perception led to stronger endorsement of the deontological position. Baer et al (1993) administered a business ethics scale and a test of locus of control. They found the largest correlations between the internal locus of control measure and a measure of emotional health in the test battery.

A veiled purpose test made for better predictions than did one calling for direct admission of misdeeds (Murphy \& Lee, 1994). Those authors also found that 'conscientiousness' is the best single predictor of scores on measures of integrity. The point here is that tests of ethical disposition need to have low face validity as otherwise they could be readily completed in an evasive fashion. The comparison of overt and personality based integrity tests was examined by Whitney et al (1999). They found that overt integrity tests were perceived as having greater face and predictive validity that were personality based integrity tests. This, of course, is comparing one concept to another rather than comparing a proposed concept to some observable empirical events. 


\section{Significance of the proposal}

The significance of this project is likely to be the successful implementation of such a means of personal selection which could result in less technical compliance problems, diminish legal transgressions, and save the costs and trouble of contentious breaches. From a theoretical point of view it would greatly enhance our understanding of a major character trait, and make a contribution to theories of individual differences.

Australian national research priorities are relevant to this notion of moral intelligence. One is that of 'Smart information use' and 'Promoting an innovation culture and economy'. The two relevant sections are 'Breakthrough sciences' and 'Smart information use'. The goal of those sections is oriented toward providing a means of enhancing the quality of Australian business, and of enhancing the quality of life in general.

One bonus benefit of the development of a means of measuring moral intelligence is the reduction of workplace stress in that a more morally oriented workforce would provide both stability and quality of human relationships. Here one of the resultant issues is 'Should the immoral be unemployed?' In the short term it does mean that they will be less readily employable: in the longer term it should have the effect of lifting standards.

The concept proposed here is significant because of growing public concern about massive corporate collapses such as Enron and $H I H$, reportedly due in no small part to unethical behaviour, and the importance of sound leadership to the future wellbeing of both business and society. The most recent example of corporate collapse is that of Opes Prime, one of the smaller Melbourne stockbroking firms. The discovery of 'irregularities', the banks holding of collateral shares as security, and the selling of shares in order to meet margin calls are all decisions that must be invested with ethical considerations.

This whole process has ruined a number of people. It is such crises of confidence, and of transparency and goodwill that ethics so clearly deals. Although one may be able to see some elements of corporate formal legal compliance that is clearly not enough. The reputation of Australian business is tarnished by instances of 'irregularities', defalcation, and of patent dishonesty. It inflicts not only reputational damage but is also destructive of the trust that is essential to business.

Among the practical reasons for developing such a test are having a ready means of measuring the ethical personality for professional training and for personnel selection in business. It should also help improve ethical performance thereby enhancing the quality of life. At the macro level it is held that the benefits of being able to identify stable intra-personal characteristics will help lift the level of ethical performance in corporate Australia. It should, thereby, result in an enhanced reputation for Australian business practices, and help advance the quality of life.

\section{Theoretical benefits}

The conceptual questions addressed in this proposal concern which approach best characterises moral intelligence? How is moral intelligence related to actual behaviour? To what extent is moral intelligence compounded with other concepts, such as locus of control? and how may moral intelligence be brought to bear in commercial situations of trading and personnel deployment.

The theoretical benefits include its contribution as a research tool in other research projects, and raising the level of understanding of the nature of ethics from an individual differences perspective. At the macro level it is held that the benefits of being able to identify stable intra-personal characteristics will help lift the level of ethical performance in corporate Australia. It should, thereby, result in an enhanced reputation for Australian business practices, as well as helping advance the quality of life. The availability of a test for ethical disposition should contribute to the national business agenda by having an objective measure available to aid the promotion and selection of ethical management. It is seen as vitally important that selection is done on Board members, and senior executives, as they set the tone and standards. 


\section{References}

Ambady N \& Rosenthal R (1993). Half a minute: Predicting teacher evaluations from thin slices of nonverbal behavior and physical attractiveness. Journal of personality and social psychology. 64 (3) 431441

American Psychiatric Association (1994). Diagnostic and statistical manual (DSM IV). American Psychiatric Association. (4th edit).

Armstrong A, Sweeney M \& Kusuma H (1999). The relationship between ethical climate and the quality of life. Paper presented to the British Academy of Management Conference, 1-3 September, Manchester.

Baehr M E, Jones J W \& Nerad A J (1993). Psychological correlates of business ethics orientation in executives. Journal of business and psychology. 7 (3) 291308

Blickle G, Schlegel A, Fassbender P \& Klein U (2006). Some Personality Correlates of Business WhiteCollar Crime.Applied Psychology: an international review. 55 (2)

Cherry J (1997). Perceived risk, locus of control, and moral philosophy: An investigation of situation and personality variables in a positive model of ethical decision making in marketing. Dissertation abstracts international. Section A: Humanities and social sciences. 57 (10 A) 4452

Collins J M \& Schmidt F L (1993). Personality, integrity, and white collar crime: A construct validity study. Personnel psychology. 1993 Sum; Vol 46 (2): 295311

Frank M G \& Ekman P (1997). The ability to detect deceit. Journal of personality and social psychology. 72 (6) 1429-1439

Goleman D (2001). The emotionally intelligent workplace: how to select for, measure, and improve emotional intelligence in individuals, groups, and organizations. San Francisco: Jossey Bass

Kohlberg L (1976). Moral stages and moralization: the cognitive developmental approach, In Moral development and behavior: theory, research and social issues. (Ed. T Lickona). NY: Holt, Rinehart \& Winston

Kohlberg, L. (1969). Stage and sequence: The cognitive-developmental approach to socialization. In D.A. (Ed.) Handbook of socialization theory and research. Chicago: Rand McNally

Lilienfeld S O, Andrews B P, Stone R \& Stone E F (1994). The relations between a self report honesty test and personality measures in prison and college samples. Journal of research in personality. 28 (2) 154169

Litwack T R (2001). Actuarial versus clinical assessments of dangerousness. Psychology, public policy and law. 7 409-443

Logan T G, Koettel R C \& Moore R W (1986). Personality correlates of a test of honesty. Psychological reports. 59 (2, Pt 2) 10151018

Logsdon J M \& Corzine J B (1999). The CEO's psychological characteristics and ethical culture. Current topics in management. 4 63-79 (have copy)*

Lubinski D (2000). Scientific and social significance of assessing individual differences: sinking shafts at a few critical points. Annual review of psychology. 51405444

Mental Measurements Yearbook. Mental measurements yearbook. Lincoln, Nebraska: The Buros Institute of Mental Measurement

Mikulay S \& Goffin R D (1998). Measuring and predicting counter productivity in the laboratory using integrity and personality testing. Educational and psychological measurement. 58 (5) 768-790

Murphy K R \& Lee S (1994). Personality variables related to integrity test scores: The role of conscientiousness. Journal of business and psychology. 8 (4) 413424

Sternberg R J (1995). Theory and measurement of tacit knowledge as a part of practical intelligence. Zeitschrift für Psychologie. 203 (4) 319-334.

Terpstra D E, Rozell E \& Robinson R K (1993). The influence of personality and demographic variables on ethical decisions related to insider trading. Journal of psychology. 127 (4) 375-389

Trevino L K, Butterfield K D \& McCabe D L (1998). The ethical context in organizations: influences on attitudes and behaviors. 8 (3) 447-476

Victor B \& Cullen J B (2001). An ethical weather report: assessing the organisation's ethical climate. Organisational dynamics. 89 (18) 2-50 
Wehrle T, Kaiser S, Schmidt S \& Scherer K R (2000). Studying the dynamics of emotional expression using synthesized facial muscle movements. Journal of personality and social psychology. 78 (1) 105-119

Whitney D J, Diaz J, Mineghino M E \& Powers K(1999). Perceptions of overt and personality-based integrity tests. International journal of selection \& assessment. 7 (1) 35-45

Woolley R M \& Hakstian A R (1992). An examination of the construct validity of personality based and overt measures of integrity. Educational and psychological measurement. 52 (2) 475-489

Zimbardo P (2007). The Lucifer effect: why good people do evil things. NY: Random House 